\title{
Pupila tônica bilateral como seqüela of tálmica isolada da doença de Lyme: relato de caso
}

\author{
Bilateral tonic pupil as the only remaining ophthalmic sign of Lyme disease: case report
}

\author{
Fernando Fugimoto ${ }^{1}$ \\ Ramon Coral Ghanem ${ }^{2}$ \\ Mário Luiz Ribeiro Monteiro ${ }^{3}$
}

Trabalho realizado na divisão de Clínica Oftalmológica do Hospital das Clínicas da Faculdade de Medicina da Universidade de São Paulo.

${ }^{1}$ Residente de terceiro ano da Clínica Oftalmológica do Hospital das Clínicas da Faculdade de Medicina da Universidade de São Paulo (USP). São Paulo (SP).

${ }^{2}$ Médico preceptor da Faculdade de Medicina da USP. São Paulo (SP)

${ }^{3}$ Professor Livre Docente do Departamento de Oftalmologia da Faculdade de Medicina da USP. São Paulo (SP). Endereço para correspondência: Fernando Fugimoto Rua João Cachoeira, 892 apto: 113B - São Paulo (SP) CEP 04535-902

E-mail: ffugimoto@yahoo.com.br

Recebido para publicação em 25.06.2004

Versão revisada recebida em 16.12.2004

Aprovação em 18.03.2005

Nota Editorial: Após concluída a análise do artigo sob sigilo editorial e com a anuência do Dr.Eric Pinheiro de Andrade sobre a divulgação de seu nome como revisor dele, agradecemos sua participação neste processo.

\begin{tabular}{|c|}
\hline RESUMO \\
\hline A doença de Lyme é afecção sistêmica causada pela espiroqueta Borrelia \\
burgdorferi, transmitida pelo carrapato. É descrita principalmente nos \\
países do hemisfério norte, sendo pouco relatada no Brasil. O objetivo \\
deste trabalho é documentar uma paciente com doença de Lyme que \\
apresentou pupila tônica bilateral como única seqüela oftálmica da afecção. \\
Trata-se de uma menina de 13 anos de idade, com diagnóstico de doença \\
de Lyme, que apresentou paralisias facial periférica e do oculomotor \\
bilaterais. Após recuperação do quadro neurológico manteve anisocoria, \\
fraco reflexo fotomotor, amplitude de acomodação inferior ao normal, \\
constrição pupilar tônica para perto e redilatação lenta em ambos os olhos. \\
Oteste compilocarpina a 0,1\% foi positivo em ambos os olhos, confirmando \\
a suspeita clínica de pupila tônica bilateral. Este é o primeiro caso relatado \\
de pupila tônica bilateral causado pela doença de Lyme.
\end{tabular}

Descritores: Pupila tônica; Doença de Lyme/diagnóstico; Doença de Lyme/complicações; Ceftriaxona/uso terapêutico; Doença de Lyme/quimioterapia; Papiledema/etiologia; Meningoencefalite; Relato de caso

\section{INTRODUÇÃO}

A doença de Lyme, originalmente denominada artrite de Lyme, foi pela primeira vez descrita em 1975 na cidade de Lyme (Connecticut - EUA), quando ocorreu um surto de artrite semelhante à artrite reumatóide juvenil. A doença é agora identificada como um distúrbio sistêmico causada pela espiroqueta transmitida pelo carrapato, a Borrelia burgdorferi ${ }^{(1-2)}$. É descrita principalmente nos países do hemisfério norte (América do Norte, Europa e Ásia) e Austrália; sendo pouco relatada na América do Sul. No Brasil, os primeiros relatos de manifestações cutâneas foram realizados em 1987 e em 1993 por Yoshinari e colaboradores ${ }^{(2)}$, que descreveram os primeiros casos de doença de Lyme com manifestações extracutâneas em pacientes com sorologia positiva, utilizando as técnicas de ELISA e Western Blotting.

As alterações oftálmicas mais comuns são: conjuntivite folicular, uveíte, coroidite, descolamento de retina, ceratite e vasculite da retina ${ }^{(3)}$. As manifestações neuro-oftalmológicas podem aparecer em qualquer estágio da doença, e geralmente se traduzem por papiledema ou neuropatias cranianas $^{(3)}$.

O objetivo deste trabalho é documentar uma paciente que foi acometida pela doença de Lyme com comprometimento do sistema nervoso central e que apresentou pupila tônica bilateral como única seqüela oftálmica.

\section{RELATO DO CASO}

Paciente de 13 anos de idade, feminina, branca, encaminhada ao Serviço de Neuro-oftalmologia do Hospital de Clínicas de São Paulo com diagnósti- 
co de doença de Lyme com queixa de ardor ocular e dificuldade de fechar ambos os olhos. A paciente foi internada três meses antes com febre, cefaléia frontal e queda do estado geral. Durante a internação desenvolveu dislalia, paralisia facial bilateral, ptose palpebral bilateral e diplopia. Referiu habitar em zona rural e contato esporádico com carrapatos. Negou ocorrência de alterações cutâneas prévias. Durante sua internação foram realizadas tomografia de crânio (TC) que não mostrou alterações e colheita de líquor (LCR) que evidenciou uma meningite linfomonocitária com 11 células $(80 \%$ de linfócitos e monócitos), $39 \mathrm{mg} / \mathrm{dl}$ de proteínas e $55 \mathrm{mg} / \mathrm{dl} \mathrm{de}$ glicose. A imagem de ressonância magnética (IRM) mostrou espessamento e realce do nervo trigêmio à esquerda, de ambos os nervos faciais, do oculomotor bilateralmente além de realce meníngeo. As sorologias obtidas com método ELISA e Western blotting no sangue e no LCR confirmaram o diagnóstico de doença de Lyme. O tratamento foi realizado com ceftriaxone $2 \mathrm{~g} /$ dia por 30 dias com grande melhora do estado geral, quando foi encaminhada para avaliação oftalmológica.

$\mathrm{O}$ exame ocular externo mostrou paresia facial periférica bilateral com lagoftalmo discreto e o exame da motilidade ocular extrínseca não apresentou alterações (Figura 1). A acuidade visual sem correção para longe era 20/20 e para perto J1 em ambos olhos.

Apresentou ao exame pupilar anisocoria, sendo a pupila do olho esquerdo (OE) maior que a do direito (OD). Em luz ambiente a pupila do OD media $4 \mathrm{~mm}$ e a do OE $5 \mathrm{~mm}$; sob estímulo luminoso intenso OD atingia $3,5 \mathrm{~mm}$ e a do $\mathrm{OE} 4 \mathrm{~mm}$, e após estímulo de convergência OD media $2,5 \mathrm{~mm}$ e a do $\mathrm{OE} 3,0 \mathrm{~mm}$ (Figura 2). Após convergência prolongada, ao retornar o olhar para longe, a re-dilatação pupilar era lenta. Trinta minutos após instilação de pilocarpina $0,1 \%$ os diâmetros pupilares, em luz ambiente normal, eram de 2,5 $\mathrm{mm}$ no OD e 3,5 mm no OE demonstrando hipersensibilidade em ambos os lados (Figura 3).

A medida da amplitude de acomodação foi realizada utilizando-se o método indireto adicionando lentes negativas constatando no OD 8,25 dioptrias e no OE 9,75 (sendo o normal para idade aproximadamente 12,5 dioptrias). A biomicroscopia apresentou ceratite inferior discreta em ambos os olhos. A pressão intra-ocular pelo tonômetro de Goldmann era de $8 \mathrm{mmHg}$ no OD e $6 \mathrm{mmHg}$ no OE. O exame de fundo de olho apresentou-se normal em ambos os olhos.

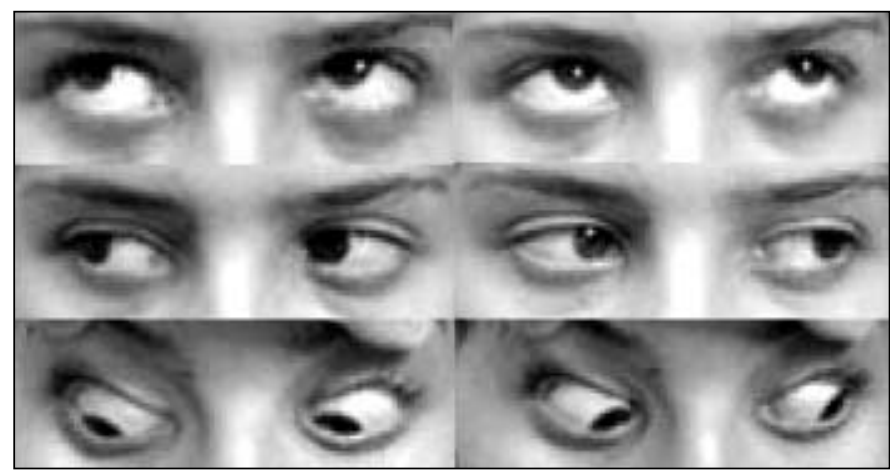

Figura 1 - Exame da motilidade ocular extrínseca sem alterações

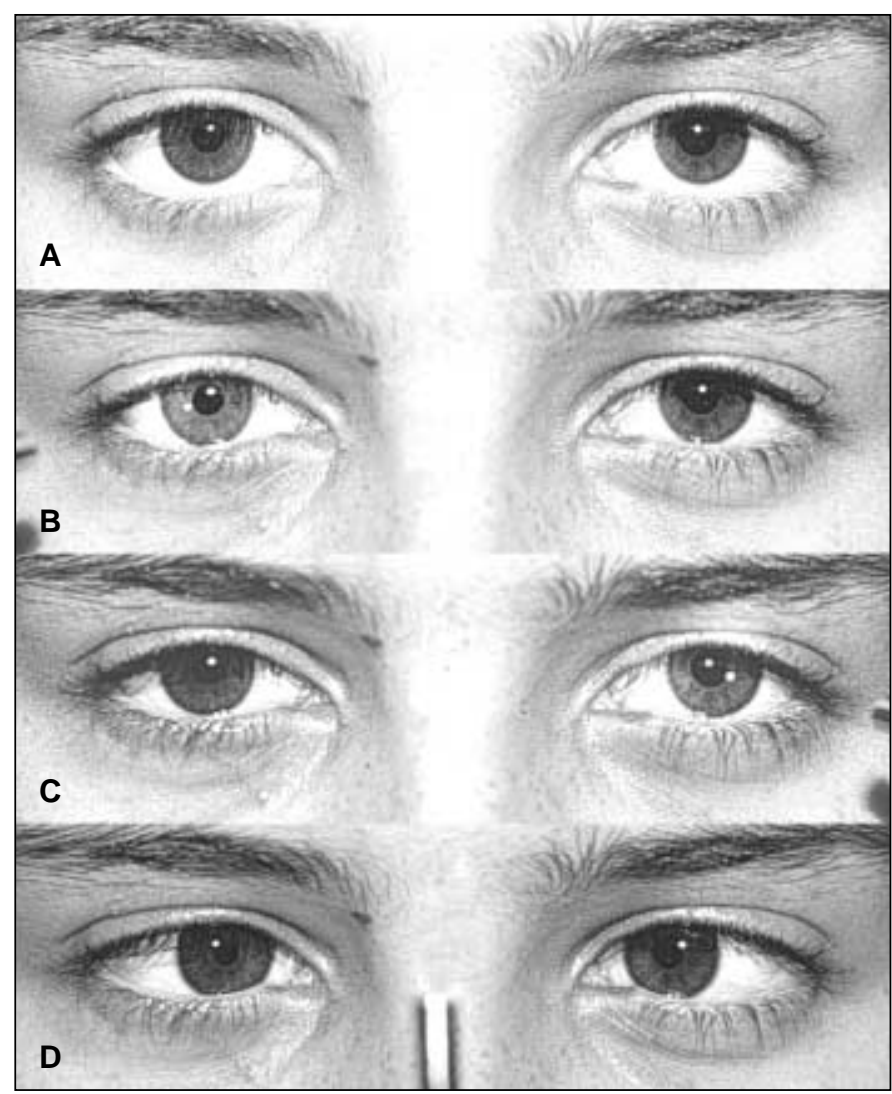

Figura 2 - A: Em luz ambiente a pupila do OD media $4 \mathrm{~mm}$ e a do $O E$ $5 \mathrm{~mm}$; sob estímulo luminoso intenso $O D$ atingia $3,5 \mathrm{~mm}(B)$ e a do $O E$ $4 \mathrm{~mm}$ (C); D: após estímulo de convergência OD media $2,5 \mathrm{~mm}$ e a do OE $3,0 \mathrm{~mm}$

\section{DISCUSSÃO}

As manifestações clínicas da doença de Lyme são caracterizadas por três estágios. O estágio I caracteriza-se pelo eritema crônico migrans, lesão patognomônica na pele acompanhada de febre, cefaléia, fadiga, mialgia e artralgia; o estágio II da doença de Lyme é caracterizado pelos sinais de disseminação com vários tipos de acometimentos: neurológico (meningite, neuropatia craniana, radiculopatia), cardíaco, reumatológico e ocasionalmente ocular; o estágio III aparece meses a anos após a infecção e freqüentemente é caracterizado pela artrite crônica, acrodermatite e encefalomielite ${ }^{(3)}$.

A Organização Mundial de Saúde preconiza que o diagnóstico deve ser baseado no quadro clínico e no estudo sorológico. O diagnóstico laboratorial é usualmente feito através do ELISA (enzyme-linked immunosorbent assay) para anticorpos IgM e IgG contra o B. burgdorferi. Para confirmar o resultado do ELISA, realiza-se o teste de Western blotting. Outro teste laboratorial diagnóstico da doença de Lyme, tem sido feito através da identificação do espiroqueta $B$. burgdorferi pelo método PCR (polymerase chain reaction) $)^{(4)}$. No caso em estudo, a doença de Lyme foi diagnosticada a partir do quadro clínico compatível, do quadro epidemiológico, da sorologia do sangue e LCR (ELISA e Western blotting). 


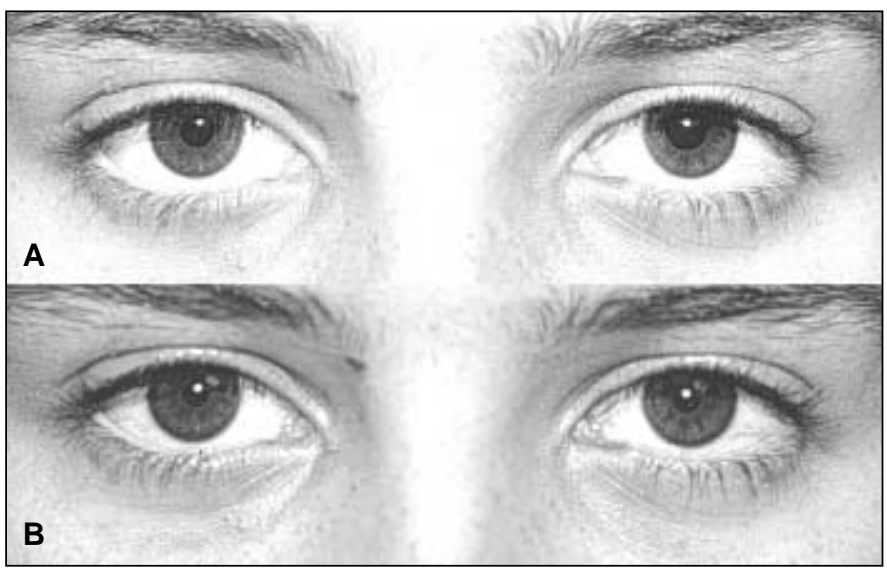

Figura 3 - A: Em luz ambiente a pupila do OD media $4 \mathrm{~mm}$ e a do $O E$ $5 \mathrm{~mm}$; B: Trinta minutos após a instilação de pilocarpina $0,1 \%$ os diâmetros pupilares, em luz ambiente, eram de $2,5 \mathrm{~mm}$ no OD e $3,5 \mathrm{~mm}$ no OE demonstrando hipersensibilidade em ambos os lados

Várias alterações neuro-oftalmológicas podem ocorrer no estágio II da doença de Lyme. Papiledema ocorre associado à meningite e meningoencefalite especialmente em crianças. Alguns autores revisaram as manifestações da doença de Lyme em 96 crianças, e destas, seis apresentaram papiledema ${ }^{(5)}$. Lesser em 1990 relatou seis casos da doença de Lyme, sendo que um paciente teve meningite com elevação da pressão intracraniana, papiledema bilateral e paralisia bilateral do nervo abducente ${ }^{(6)}$ Acometimento do nervo óptico com neurite óptica ou neuroretinite também pode ocorrer ${ }^{(3,6)}$. Neuropatias cranianas geralmente acompanham a meningite, sendo a paralisia facial unilateral ou bilateral a mais freqüente ${ }^{(3)}$. O mecanismo proposto para as neuropatias cranianas associadas à afecção inclui inflamação local no espaço subaracnóideo ou invasão do nervo pela espiroqueta. As paralisias do VI nervo podem ocorrer também por hipertensão intracraniana. Embora as alterações de motilidade ocular sejam raras, podemos encontrar paralisia de abducente, oculomotor e troclear ${ }^{(3)}$. Em nosso caso, a paciente apresentou inicialmente paralisia bilateral do facial e paresia bilateral do oculomotor com recuperação completa da movimentação ocular (Figura 1).

Nossa paciente apresentou o achado incomum de pupila tônica, presumivelmente decorrente do acometimento do sistema nervoso central pela doença de Lyme da qual vinha se recuperando. A pupila tônica é caracterizada por uma reação fraca a luz, paralisia de acomodação, hipersensibilidade colinérgica do músculo constrictor denervado, resposta pupilar forte e tônica ao estímulo de perto e re-dilatação lenta e tônica após constrição pelo estímulo para perto ${ }^{(7)}$. Quando idiopática (pupila tônica de Adie) o acometimento geralmente é unilateral $(80 \text { a } 90 \%)^{(7)}$. Os testes farmacológicos auxiliam o diagnóstico de pupila tônica, apesar de não serem patognomônicos. Observa-se constrição pupilar após a instilação de pilocarpina diluída a $0,1 \%$, o que não ocorre com pupilas normais.

No caso relatado observamos uma dissociação luz-perto, com constrição pupilar tônica para perto e re-dilatação lenta, sendo características que levaram à suspeita de pupila tônica. Foi realizado teste com pilocarpina a $0,1 \%$ à procura de hipersensibilidade colinérgica denervacional que foi positivo ${ }^{(7)}$. Foi também realizada a avaliação da amplitude de acomodação que demonstrou valores inferiores ao esperado para a idade, auxiliando a estabelecer o diagnóstico de pupila tônica.

Anormalidades pupilares já foram relatadas em poucos pacientes com doença de Lyme. Pupila de Argyl-Robertson é mencionada em uma revisão sobre alterações neurológicas da doença e síndrome de Horner reversível foi descrita em um paciente com a fase aguda da doença ${ }^{(3)}$. Quanto à pupila tônica, observada em nossa paciente, encontramos apenas duas citações prévias sobre o tema. Alguns autores mencionam a ocorrência de pupila tônica, embora não encontrando nenhuma referência do assunto na revisão cuidadosa deste $\operatorname{artigo}^{(3,6)}$. Outros autores, no entanto, recentemente relataram 3 casos de pupila tônica em pacientes com a afecção confirmando a possibilidade de sua ocorrência ${ }^{(8)}$. Estes autores observaram em uma casuística de 140 casos de pacientes com a borreliose, 3 indivíduos que tinham sintomas predominantemente neurológicos e que apresentaram pupila tônica unilateral. Nosso paciente representa, portanto, o primeiro caso de pupila tônica bilateral nesta condição.

Embora os relatos de pupila tônica sejam muito escassos nesta moléstia, anormalidades pupilares são freqüentes na sífilis $^{(9)}$, uma condição também causada por espiroqueta que compartilha de diversas manifestações neurológicas e oftálmicas com a borreliose. Pupila tônica já foi bem documentada na sífilis ${ }^{(10-11)}$ e muitos autores sugerem que na presença de um paciente com pupila tônica o diagnóstico de sífilis deva ser considerado $^{(9,11)}$, obtendo-se uma sorologia adequada para tal afecção. Nossa paciente serve, portanto, para enfatizar que na presença deste tipo de afecção pupilar, a doença de Lyme também deva ser incluída no diagnóstico diferencial, especialmente em regiões endêmicas para a doença.

É difícil definir com exatidão o local da lesão responsável pelas anormalidades pupilares em nossa paciente, o mesmo ocorrendo em muitos casos de neurosífilis ${ }^{(11)}$. De maneira geral considera-se que a pupila tônica se deva a uma lesão da via parassimpática pós-ganglionar já que a hipersensibilidade (de denervação) à pilocarpina diluída, observada na maioria dos casos de pupila tônica, aponta nesta direção. Na borreliose, assim como na sífilis ${ }^{(11)}$, o acometimento do sistema nervoso central poderia acompanhar alteração do gânglio ciliar, levando à pupila tônica.

O conceito de que a hipersensibilidade de denervação seja causada apenas por acometimento do gânglio ciliar, no entanto, pode ser questionado levando-se em conta alguns estudos que demonstraram hipersensibilidade da pupila também em lesões pré-ganglionares do nervo oculomotor ${ }^{(12-13)}$. Além disso, outro trabalho relatou casos pupila tônica típica após paralisia oculomotora $^{(14)}$. Nossa paciente se mostra semelhante a estes casos já que referia ter apresentado uma paresia oculomotora no início da doença. É difícil definir, portanto, se a lesão responsável pelas anormalidades pupilares em nossa paciente se situou no 
gânglio ciliar ou se foi decorrente da paralisia oculomotora prévia. De qualquer forma não havia qualquer anormalidade residual na movimentação ocular (Figura 1) e o único achado oftálmico era mesmo a pupila tônica bilateral.

Em conclusão, nosso trabalho relata o primeiro caso de pupila tônica bilateral decorrente de acometimento do sistema nervoso central pela doença de Lyme. O estudo desta paciente serve para enfatizar que tal afecção deve ser incluída no diagnóstico diferencial dos indivíduos com pupila tônica, especialmente em regiões endêmicas para doença de Lyme.

\section{ABSTRACT}

Lyme disease is a multisystemic disorder caused by Borrelia burgdorferi spirochete, transmitted by ticks. Mainly described in the northern hemisphere and rarely in Brazil. The purpose of this report is to describe a patient with Lyme disease who developed bilateral tonic pupil as the only remaining sign. A 13-year-old female with Lyme disease, presented with bilateral peripheral facial and oculomotor paralysis. After recovery from neurological abnormalities the patient sustained anisocoria, reduced fotomotor reflex, less than normal amplitude of accommodation, tonic pupil constriction for near objects and slow redilatation in both eyes. Dilute $0.1 \%$ pilocarpine test was positive in both eyes, confirming the suspicion of bilateral tonic pupil. This is the first case report of bilateral tonic pupil caused by Lyme disease.

Keywords: Tonic pupil; Lyme disease/diagnosis; Lyme disease/complications; Ceftriaxone/therapeutic use; Lyme disease/ drug therapy; Papilledema/etiology; Meningoencephalitis; Case report

\section{REFERÊNCIAS}

1. Yoshinari NH, Oyafuso LK, Monteiro FGV, Barros PJL, Cruz FCM, Ferreira GE, et al. Doença de Lyme. Relato de um caso observado no Brasil. Rev Hosp Clin Fac Med S Paulo. 1993;48(4):170-4

2. Yoshinari NH, Barros PJL, Bonoldi VLN, Ishikawa M, Battesti DMB, Pirana $\mathrm{S}$, et al. Perfil da borreliose de Lyme no Brasil. Rev Hosp Clin Fac Med S Paulo. 1997;52(2):111-7.

3. Balcer LJ, Winterkorn JM, Galetta SL. Neuro-ophthalmic manifestations of Lyme disease. J Neuroophthalmol. 1997;17(2):108-21.

4. Magnarelli LA. Current status of laboratory diagnosis for Lyme disease. Am J Med. 1995;98(Suppl 4A):10S-12S.

5. Belman AL, Iyer M, Coyle PK, Dattwyler R. Neurologic manifestations in children with North American Lyme disease. Neurology. 1993;43(12):2609-14.

6. Lesser RL, Kornmehl EW, Pachner AR, Kattah J, Hedges TR, Newnan NM, et al. Neuro-ophthalmologic manifestations of Lyme Disease. Ophthalmology. 1990;97(6):699-706

7. Miller NR. Walsh and Hoyt's clinical neuro-ophthalmology. $4^{\text {th }}$ ed. Baltimore: Williams \& Wilkins; 1985. p.3636-90.

8. Stricker RB, Winger EE. Holmes-Adie syndrome and Lyme disease. Lancet. 2001;357(9258):805.

9. Lesser RL. Spirochetes and the spirochetoses. In: Miller NR, Newman NJ, editors. Walsh \& Hoyt's clinical neuro-ophthalmology. $5^{\text {th }}$ ed. Baltimore: Williams \& Wilkins; 1995. p.4779-944.

10. Sundaram MB. Pupillary abnormalities in congenital neurosyphilis. Can J Neurol Sci. 1985;12(2):134-5.

11. Fletcher WA, Sharpe JA. Tonic pupils in neurosyphilis. Neurology. 1986; 36(2): 188-92.

12. Ponsford JR, Bannister R, Paul EA. Methacholine pupillary responses in third nerve palsy and Adie's syndrome. Brain. 1982;105(Pt 3):583-97.

13. Jacobson DM. Pupillary responses to dilute pilocarpine in preganglionic 3rd nerve disorders. Neurology. 1990;4(5):804-8.

14. Coppeto JR, Ribeiro Monteiro ML, Young D. Tonic pupils following oculomotor nerve palsies. Ann Ophthalmol. 1985;17(9):585-8. 